\title{
Epidemiology of Traumatic Brain Injury in Georgia: A Prospective Hospital-Based Study
}

This article was published in the following Dove Press journal:

Risk Management and Healthcare Policy

\author{
Eka Burkadze' \\ Ketevan Axobadze (iD) \\ Nino Chkhaberidze (D) \\ Nino Chikhladze' \\ Madalina Adina Coman ${ }^{2}$ \\ Diana Dulf ${ }^{2}$ \\ Corinne Peek-Asa ${ }^{3}$ \\ 'Department of Public Health, Faculty of \\ Medicine, Ivane Javakhishvili Tbilisi State \\ University, Tbilisi, Georgia; ${ }^{2}$ Department \\ of Public Health, College of Political, \\ Administrative and Communication \\ Sciences, Babes-Bolyai University, Cluj- \\ Napoca, Romania; ${ }^{3}$ Department of \\ Occupational and Environmental Health, \\ College of Public Health, University of \\ lowa, lowa City, IA, USA
}

Correspondence: Eka Burkadze

Department of Public Health, Faculty of Medicine, Ivane Javakhishvili Tbilisi State University, I Chavchavadze Ave, Tbilisi, 0179 , Georgia

$\mathrm{Tel}+995591$ II 8090

Email eka.burkadze@tsu.ge
Purpose: Traumatic brain injury (TBI) is one of the major causes of morbidity and mortality worldwide, disproportionally affecting low- and middle-income countries (LMICs). Epidemiological characteristics of TBI at a national level are absent for most LMICs including Georgia. This study aimed to establish the registries and assess causes and outcomes in TBI patients presenting to two major trauma hospitals in the capital city -Tbilisi. Patients and Methods: The prospective observational study was conducted at Acad. O. Gudushauri National Medical Center and M. Iashvili Children's Central Hospital from March, 1 through August, 31, 2019. Patients of all age groups admitted to one of the study hospitals with a TBI diagnosis were eligible for participation. Collected data were uploaded using the electronic data collection tool -REDCap, analyzed through SPSS software and evaluated to provide detailed information on TBI-related variables and outcomes using descriptive statistics.

Results: Overall, 542 hospitalized patients were enrolled during the study period, about $63 \%$ were male and the average age was 17.7 . The main causes of TBI were falls $(58 \%)$ and struck by or against an object (22\%). The 97\% suffered from mild TBI (GCS 13-15). Over $23 \%$ of patients arrived at the hospital more than 1 hour after injury and $25 \%$ after more than 4-hours post-injury. Moderate and severe TBI were associated with an increased hospital length of stay. Mortality rate of severe TBI was $54 \%$.

Conclusion: This study provides important information on the major epidemiological characteristics of TBI in Georgia, which should be considered for setting priorities for injury management.

Keywords: traumatic brain injury, injury epidemiology, registry, Georgia

\section{Introduction}

Traumatic brain injury (TBI) is an important public health and socio-economic problem worldwide, disproportionally affecting low- and middle-income countries (LMICs) where the $85 \%$ of global population reside. ${ }^{1-7}$ TBI is a dominant cause of mortality, particularly among young adults, as well as a leading cause of permanent disability among survivors. ${ }^{1,2,8,9}$ According to the World Health Organization (WHO), TBI will become the third leading cause of mortality amongst all age groups by the year $2020 .^{10}$

The majority of TBI research comes from high-income countries, especially in Western Europe and North America, and much of the research is possible due to the presence of trauma registries. $^{3,4,11}$ Despite high and growing rates of TBI in LMICs, there are many critical gaps in knowledge of TBI that need to be addressed. Lack of good quality data on TBI is a disruptive factor in estimating the true burden 
and magnitude of TBI as well as in identifying possible modifiable risk factors associated with injury occurrence. $^{5,12,13}$

Georgia is a low-middle income country in the Caucasus region of Eurasia. Located at the crossroads of western Asia and eastern Europe, more than $67 \%$ of the population is between 15 and 64, the age range with the highest rate of TBI. ${ }^{14}$ According to the National Center for Disease Control and Public Health of Georgia (NCDC), in 2018, 10,958 individuals were admitted to the hospital for TBI, of whom 137 (1.25\%) died. Georgia, an emerging economy with a high rate of traumatic brain injuries, has no national or hospital-based trauma registries. Lack of data is one reason that no studies have been published to describe trends and characteristics of TBI-related hospitalizations. With the goal of understanding the characteristics of TBI for planning and implementing effective preventive measures, TBI trauma registries were established in the two major trauma hospitals treating pediatric and adult TBIs in Georgia.

\section{Patients and Methods}

The data reported here were collected as a part of the project INITIatE: International Collaboration to Increase Traumatic Brain Injury Surveillance in Europe, funded by the United States National Institutes of Health and led by the University of Iowa and the Cluj School of Public Health (NIH/NINDS R21NS098850). We conducted a prospective observational study from March, 1 to August, 31, 2019 within two high-volume trauma hospitals. The two hospitals were selected because they have the highest trauma patient volume; one serves adults and has 320 beds (Academician O. Gudushauri National Medical Center) and the second is a pediatric hospital with 266 hospital beds (M. Iashvili Children's Central Hospital). Both hospitals are located in the capital city of Tbilisi (population 1175 200) and serve the country (population 3716 900) in providing Level I trauma care. All patients admitted to one of the study hospitals with a TBI diagnosis (ICD 10 codes:S00-S09.0) were eligible for participation. Trained research personnel identified admitted patients that met study criteria and then collected information through medical record review and discussion with the treating medical team. The researchers did not interact with the patient directly; any communication with the patient was conducted by the medical team for the purposes of completing the medical record. This project was approved by the Georgian National Centre for Disease Control and Public Health Institutional Review Board.

The TBI registry variables and codebook were developed through a participatory and iterative process. First, sample registries were identified using a literature search and by contacting investigators with funded TBI registry projects (funded through NIH and the EU). A set of core variables and a codebook were developed with expert opinion input and the study team, and once finalized the registry was pilot tested using medical records in each of the hospitals. Medical records were insufficient in providing the detail needed to complete the registry information, so a prospective registry design was established.

The study variables included: demographics (age, gender, employment and social role), mechanism and intent of injury, type of admission, admission GCS, diagnostics, management and treatment (I e length of hospital stay, discharge GCS and mortality).TBI severity was measured using the Glasgow Coma Scale (GCS) scores at admission, and the patients were categorized into three groups: mild (13-15), moderate (9-12), and severe (3-8).

Data was collected on paper forms and uploaded into a REDCap electronic database, a secure web application used for developing and managing surveys and databases. Monthly data quality checks were conducted to ensure high-quality data collection. Once entered, cleaned, and quality checked, the final database was exported to SPSS for analysis. TBI-related variables were examined using descriptive statistics. Demographic and injury characteristics were examined in relation to the outcomes of hospital length of stay and status (discharged home, discharged to rehabilitation, died, and unknown). Place of occurrence was examined with respect to age categories. Clinical features including TBI severity, CT scan results, injury diagnoses, and procedures including surgery,ventilation, and medication were examined by hospital length of stay and discharge status, which were outcome measures used to indicate severity. Differences in categorical variables were tested with chi-square tests of independence.

\section{Results}

\section{Patient Characteristics}

During the period under study, a total of 542 TBI-related hospitalizations were studied, of which $63 \%(n=341)$ were male and $37 \%(n=201)$ were female, giving a male to female ratio of 1.7:1. The age of patients ranged from 1 month to 94 years. The average age was 17.7 and the median age was 
11.1, which is reflective more of our sample of one pediatric and one adult hospital than the population distribution of TBI. The modal age group was $0-14$ accounting for 337 (62\%) patients, followed by 15-24 years accounting for 77 (14\%) patients. In accordance with the age distribution, 247 $(45 \%)$ of the hospitalized patients were students, and the next most common social role was unemployed, accounting for $115(21 \%)$ patients.

Most of the patients ( $\mathrm{n}=483,89 \%)$ sustained an injury in an urban area and the top place of TBI occurrence was at home $(\mathrm{n}=175,32 \%)$. Most of the TBI hospitalizations $(n=514,95 \%)$ were due to unintentional injuries, and only $2 \%(n=9)$ of patients suffered from work-related injuries. Among all age groups, the predominant mechanism of injury was falls $(58 \%)$ mostly $(60 \%)$ occurring among males. Struck by or against object was the second most common cause after falls with $22 \%$, followed by road traffic injuries at $15 \%(\mathrm{n}=82)$. Most road traffic injuries $(\mathrm{n}=22,68 \%)$ occurred among vehicle passengers followed by car drivers $(n=10,31 \%)$. Nearly half of the patients injured as a passenger in a vehicle $(\mathrm{n}=10,45 \%)$ were under the age of 12 , of which only 1 was secured in a child restraint. Most (75\%) of the patients above age 12 were wearing seat belts. Pedestrians accounted for $30 \%(n=25)$ of road traffic injuries, cyclists accounted for $15 \%(n=12)$, and motorcyclists accounting for $11 \%(n=9)$. Of the bicycle and motorcyclists, $38 \%(\mathrm{n}=8)$ were wearing helmets (Figure 1).

Most cases of falls happened in the age group of 0-14 and 25-44, while struck by or against object was the most common cause of TBI hospitalization among 0-14 and 15-24 age groups, most occurring among males (78\%). The majority $25 \%(n=30)$ of injuries caused by struck by

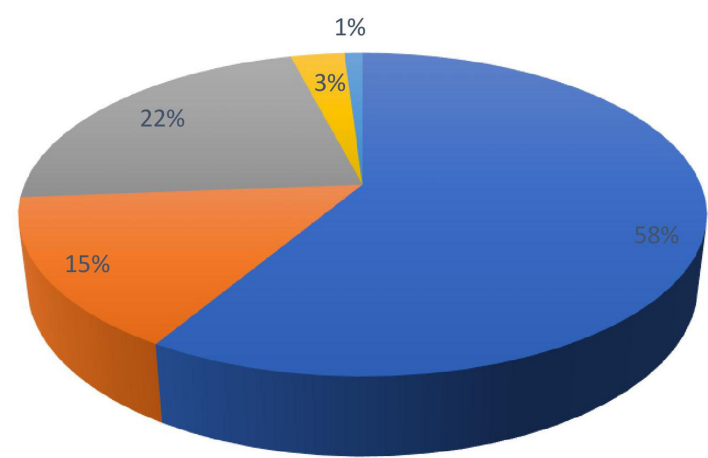

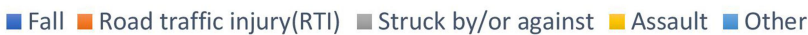

Figure I Mechanism of injury. or against object occurred in a sports and athletics area, followed by home at $21 \%(\mathrm{n}=25)$. Two-thirds of assault injuries took place in a public place, $5 \%(\mathrm{n}=1)$ at workplace, $5 \%(n=1)$ at home and $17 \%(n=4)$ at other locations. The majority $(78 \%)$ cases of assault occurred among males. The highest male:female ratio $(3: 1)$ was for injuries caused by assault (violence), and the lowest in falls (1.5:1). (Tables 1 and 2)

\section{Pre-Hospital Care}

Ambulances were the source of hospital arrival for $60 \%$ of cases $(n=328)$, and $27 \%$ arrived by private/public transport. For nearly a quarter $(23 \%)$ of the TBI patients took less than 1 hour to reach the hospital. Most of the patients (29\%) experienced an injury to arrival timeframe of 1-2 hours, $23 \%$ of patients took $2-4$ hours, and $25 \%$ arrived more than four-hour post-injury. The mean GCS was 14.7 with $97 \%$ ( $\mathrm{n}=525)$ suffering from mild TBI (GCS 13-15), $1 \%(\mathrm{n}=5)$ with moderate TBI (GCS 9-12) and $2 \%(\mathrm{n}=11)$ with severe TBI (GCS 3-8).

\section{Emergency Department Assessment and Treatment}

Most patients had stable vital signs at arrival Four percent was hypotensive (systolic blood pressure less than $90 \mathrm{~mm} \mathrm{Hg}), 1.8 \%(\mathrm{n}=10)$ were hypoxic $(\mathrm{O} 2 \mathrm{Sat}$ less than $92 \%)$, and $0.7 \%(\mathrm{n}=4)$ had fever $\left(37.5^{\circ} \mathrm{C}\right.$ and above). In $97 \%$ of the cases, the airway was clear, and breathing was spontaneous and adequate for $96 \%$ ( $\mathrm{n}=$ 520). Among the patients with breathing insufficiency, intubation was performed for $2 \%(\mathrm{n}=12)$ and manual breath support for another $1 \%(\mathrm{n}=4)$. Fluids were started for $2 \%(n=10)$, vasopressors in $2 \%(n=11)$ and CPR in only one patient (Table 3). Alcohol screening was performed in only $9 \%$ of cases, and only $3 \%$ of patients had indications of alcohol use, of which all were men and $75 \%$ were injured in a fall.

\section{Inpatient Diagnostic and Treatment}

A CT scan was performed for $430(79 \%)$ patients and showed abnormalities in $85(20 \%)$ cases. Out of these, the CT classification was indicated in 81 cases: diffuse injury, no visible pathology (NVP) was seen in 56\% $(n=45)$, diffuse injury in $27 \%(n=22)$, diffuse injury with swelling in $11 \%(\mathrm{n}=9)$, diffuse injury with shift in $5 \%$ $(\mathrm{n}=4)$ and mass lesions in $1 \%(\mathrm{n}=1)$; including subdural 
Table I Length of Stay by Demographic and Epidemiologic Factors

\begin{tabular}{|c|c|c|c|c|c|}
\hline & 0 to I Day & 2-7 Days & 8-15 Days & More Than I5 Days & Total \\
\hline & $\mathbf{N}(\%)$ & $\mathbf{N}(\%)$ & $\mathbf{N}(\%)$ & $\mathbf{N}(\%)$ & \\
\hline \multicolumn{6}{|l|}{ Gender* } \\
\hline Male & $185(6 \mid)$ & $131(63)$ & $13(72)$ & $12(80)$ & $34 I(63)$ \\
\hline Female & $116(39)$ & $77(37)$ & $5(28)$ & $3(20)$ & $201(37)$ \\
\hline \multicolumn{6}{|l|}{ Age* } \\
\hline $00-14$ & $23 I(77)$ & $97(47)$ & $8(44)$ & $I(7)$ & $337(62)$ \\
\hline I5-24 & $36(12)$ & $36(17)$ & $3(17)$ & $2(13)$ & $77(14)$ \\
\hline $25-44$ & $25(8)$ & $32(15)$ & $4(22)$ & $6(40)$ & $67(12)$ \\
\hline $45-64$ & $5(2)$ & $25(I 2)$ & $2(11)$ & $4(27)$ & $36(7)$ \\
\hline $65+$ & $4(1)$ & I8(9) & $I(6)$ & $2(13)$ & $25(5)$ \\
\hline \multicolumn{6}{|l|}{ Mechanism* } \\
\hline Fall & 162(54) & $140(67)$ & $8(44)$ & $5(33)$ & $315(58)$ \\
\hline Road traffic injury (RTI) & $43(14)$ & $26(13)$ & $6(33)$ & $7(47)$ & $82(15)$ \\
\hline Struck by/or against & $85(28)$ & $32(15)$ & $2(11)$ & $I(7)$ & $120(22)$ \\
\hline Assault (Violence) & $8(3)$ & $5(2)$ & $2(11)$ & $2(13)$ & $17(3)$ \\
\hline Other & $3(1)$ & $5(2)$ & $0(0)$ & $0(0)$ & $8(1)$ \\
\hline \multicolumn{6}{|l|}{ Mode of arrival* } \\
\hline Ambulance and police & $182(60)$ & $125(60)$ & $11(6 I)$ & $\mathrm{II}(73)$ & $329(61)$ \\
\hline Private/public vehicle & II4(38) & $74(36)$ & $3(17)$ & $I(7)$ & $192(35)$ \\
\hline and walk-in & & & & & \\
\hline Other & $5(2)$ & $9(4)$ & $4(22)$ & $3(20)$ & $21(4)$ \\
\hline \multicolumn{6}{|l|}{$\begin{array}{l}\text { Period between time of } \\
\text { injury and attendance* }\end{array}$} \\
\hline I hour & $6 I(20)$ & $55(26)$ & $3(17)$ & $6(40)$ & $125(23)$ \\
\hline I-2 hour & $102(34)$ & $50(24)$ & $3(17)$ & $I(7)$ & $156(29)$ \\
\hline 2-4 hours & $75(25)$ & $44(21)$ & $4(22)$ & $I(7)$ & $124(23)$ \\
\hline \multirow[t]{2}{*}{ More than 4 hours } & $63(21)$ & $59(28)$ & $8(44)$ & $7(47)$ & $137(25)$ \\
\hline & $301(56)$ & 208(38) & $18(3)$ & $15(3)$ & $542(100)$ \\
\hline
\end{tabular}

Note: ${ }^{*} p<0.05$ for the chi-square test of independence.

Table 2 Place of TBI Occurrence for Different Age Groups

\begin{tabular}{|c|c|c|c|c|c|}
\hline \multirow[t]{2}{*}{ Place of Occurrence } & \multicolumn{5}{|c|}{ Age Groups } \\
\hline & $\begin{array}{l}\text { 00-14 } \\
\text { N (\%) }\end{array}$ & $\begin{array}{l}\text { I5-24 } \\
\text { N (\%) }\end{array}$ & $\begin{array}{l}25-44 \\
N(\%)\end{array}$ & $\begin{array}{l}45-64 \\
N(\%)\end{array}$ & $\begin{array}{c}65+ \\
\text { N (\%) }\end{array}$ \\
\hline Home/residential institution & $191(57)$ & $24(31)$ & $2 I(3 I)$ & $22(61)$ & $16(64)$ \\
\hline Transport area & $39(12)$ & $2 I(27)$ & $30(45)$ & $I I(3 \mid)$ & $7(28)$ \\
\hline School, educational area & 18(5) & $2(3)$ & $0(0)$ & $0(0)$ & $0(0)$ \\
\hline Recreational, cultural, or sports and athletics area & $76(23)$ & $25(32)$ & 3(4) & $0(0)$ & $\mathrm{I}(4)$ \\
\hline Other/unknown & $17(5)$ & $6(7)$ & $13(19)$ & $3(8)$ & $\mathrm{I}(4)$ \\
\hline
\end{tabular}

hematoma $(n=15)$, epidural haemorrhage $(n=13)$, and skull fracture $(n=62)$. X-ray was performed for 43 cases and showed normal results for all (100\%) patients (Table 4$)$.
A number of $83 \%(n=451)$ patients sustained mostly isolated head injury, while the $17 \%(n=91)$ of patients had injuries involving multiple body regions. Surgery was 
Table 3 ED Assessment, Vital Signs

\begin{tabular}{|c|c|c|c|c|}
\hline Vital Signs & Mean \pm SD & Range & Median & Mode \\
\hline Systolic blood pressure $(\mathrm{mmHg} ; 0-300)$ & $107.3 \pm 19.8$ & $200-65$ & 98.0 & 97.0 \\
\hline Diastolic blood pressure $(\mathrm{mmHg} ; 0-300)$ & $69.2 \pm 9.6$ & $110-35$ & 67.0 & 70.0 \\
\hline Respiratory rate (cycles per min.) & $25.9 \pm 6.4$ & $82-5$ & 27.0 & 20.0 \\
\hline Heart rate (beats per min; $0-300$ ) & $90.4 \pm 16.8$ & $145-58$ & 87.0 & 80.0 \\
\hline Human body temperature $C(0-50$ deg. $C)$ & $36.5 \pm 0.2$ & $38-36$ & 36.5 & 36.5 \\
\hline
\end{tabular}

performed for 19 patients (4\%), while 36 patients $(7 \%)$ had the surgery scheduled but not provided. Only nonoperative treatment was provided for 168 patients. A number of 22 patients received mechanical ventilation, and the 29 received antiseizure medication, hyperosmolar medication was provided for 168 patients. ICP monitor/ ventriculostomy was placed only in 1 patient. Daily therapy intensity was documented in $100 \%$ of cases. For $93 \%$ $(n=506)$ of patients it was classified as therapy intensity level (TIL) 0 , for $4 \%(n=21)$ as TIL 1 - Basic ICU care, for $2 \%(n=11)$ as TIL $2-$ mild and for $1 \%(n=4)$ as TIL 3 - moderate.

\section{Outcome}

The length of hospital stay (LOS) and discharge status were related to injury severity and varied from 0 to 37 days, the median duration of hospital stay was 1 day and the modal length of stay 1 day, respectively. Less than $1 \%$ of admitted TBI patients died, and $95 \%(\mathrm{n}=509)$ were discharged to their home. The main cause of fatal TBI by mechanism was road traffic injury (4 of 6 deaths), of which two were car drivers wearing seatbelts, one was an unrestrained child, and one was a pedestrian. Of the two remaining deaths, one was an assault and one was work-related. Analysis of deaths by age and gender: 1 ( $0-14$ years), 3 (25-44 years), 2 (45-64 years). All deceased patients were male. The patients with fatal TBIs presented at ED with varying GCS scales and varying duration from the time of injury occurrence. The GCS score ranged from 3 to 5 , and only two patients were presented to the hospital within 1 hour after injury occurrence. The two patients experienced an injury to arrival timeframe of 2-4 hours, and 2 patients arrived more than 6 hours post-injury (Table 5).

Demographic factors were all associated with length of stay $(\mathrm{p}<0.05)$. Among the patients with hospital stays longer than 1 week, more than three quarters were male.
Pediatric patients, who generally had lower TBI severity, had shorter lengths of stay than adults; $40 \%$ of $25-44$ year old and $27 \%$ of $45-64$ year old were in the hospital for 15 days or more. Falls and road traffic injury had the longest lengths of hospital stay, and $47 \%$ of road traffic injuries led to a length of stay of 15 days or more. The longest lengths of stay were among patients who arrived at the hospital by ambulance, and those with the longest delays in hospital arrival (more than 4 hours) had the longest hospital stays.

\section{Discussion}

To the best of our knowledge, this is the first prospective TBI study to be conducted in Georgia. Our study conducted information in the two largest hospitals in Tbilisi, Georgia, designed to collect detailed TBI socio-demographic, epidemiologic, management and outcome characteristics employing an electronic data collection tool. Although the National Center for Disease Control and Public Health of Georgia (NCDC) collects data on hospitalizations, these data do not include details on the type, manner, and outcomes of traumatic injuries. Thus, registries such as this are critical to inform healthcare institutions, government leaders, and public health professionals about the trends and characteristics of TBI so that prevention and treatment priorities can be identified.

Georgia has a similar trend as other countries related to TBI. For example, men have higher TBIs than women, which might be related to societal roles and high engagement in risky activities. ${ }^{15-18}$ As with TBI registries in other countries, the majority of patients sustained mild TBI. ${ }^{8,17}$ Prior studies have found that many survivors of TBI have cognitive and physical symptoms, further contributing to the large body of evidence that even mild TBI is associated with long-lasting problems of functioning, especially among young children. ${ }^{8,19,20}$ 
Table 4 Clinical Features and Length of Stay

\begin{tabular}{|c|c|c|c|c|c|c|}
\hline & 0 to I Day & 2-7 Days & 8-15 Days & $\begin{array}{l}\text { More Than } 15 \\
\text { Days }\end{array}$ & \multirow[t]{2}{*}{ Total } \\
\hline & & $\mathbf{N}(\%)$ & $\mathbf{N}(\%)$ & $\mathbf{N}(\%)$ & $\mathbf{N}(\%)$ & \\
\hline \multicolumn{2}{|c|}{ GCS score at admission* } & & & & & \\
\hline \multicolumn{2}{|l|}{ Mild } & $300(100)$ & 205(99) & $15(88)$ & $5(33)$ & 525(97) \\
\hline \multicolumn{2}{|c|}{ Moderate } & $0(0)$ & $2(I)$ & $I(6)$ & $2(13)$ & $5(1)$ \\
\hline \multicolumn{2}{|l|}{ Severe } & $I(0)$ & $I(0)$ & $I(6)$ & $8(54)$ & $I I(2)$ \\
\hline \multicolumn{2}{|l|}{ CT scan* } & & & & & \\
\hline \multicolumn{2}{|c|}{ Abnormal } & $10(3)$ & $50(24)$ & $13(72)$ & $12(88)$ & $85(16)$ \\
\hline \multicolumn{2}{|l|}{ Normal } & $194(64)$ & I44(69) & $4(22)$ & $3(20)$ & $345(64)$ \\
\hline \multicolumn{2}{|l|}{ Missing } & $97(32)$ & $14(7)$ & $I(6)$ & $0(0)$ & $I \mid 2(2 I)$ \\
\hline \multicolumn{2}{|c|}{ CT diagnosis* } & & & & & \\
\hline \multicolumn{2}{|c|}{ Traumatic cerebral edema } & $0(0)$ & $2(1)$ & $0(0)$ & $\mathrm{I}(3)$ & $3(1)$ \\
\hline \multicolumn{2}{|c|}{$\begin{array}{l}\text { Focal traumatic brain injury } \\
\text { (hematoma) }\end{array}$} & $3 I(52)$ & $70(43)$ & $13(45)$ & II (33) & $125(44)$ \\
\hline \multicolumn{2}{|c|}{ Epidural haemorrhage } & $0(0)$ & $8(5)$ & $4(14)$ & $I(3)$ & $13(5)$ \\
\hline \multicolumn{2}{|c|}{ Traumatic subdural haemorrhage } & $\mathrm{I}(2)$ & $4(2)$ & $4(14)$ & $6(18)$ & I5(5) \\
\hline \multicolumn{2}{|c|}{$\begin{array}{l}\text { Secondary diffuse traumatic brain } \\
\text { injury }\end{array}$} & $0(0)$ & $\mathrm{I}(\mathrm{I})$ & $0(0)$ & $3(9)$ & $4(1)$ \\
\hline \multicolumn{2}{|c|}{$\begin{array}{l}\text { Other/Unspecified intracranial } \\
\text { injury }\end{array}$} & $28(47)$ & $77(48)$ & $8(28)$ & II (33) & $124(44)$ \\
\hline \multicolumn{7}{|c|}{ Types of injury* } \\
\hline \multicolumn{2}{|c|}{$\begin{array}{l}\text { Soft tissue injury to the scalp, face, } \\
\text { or neck }\end{array}$} & $183(37)$ & $170(40)$ & $18(37)$ & $15(32)$ & $386(38)$ \\
\hline \multicolumn{2}{|c|}{ Fracture of the skull } & $6(1)$ & $4 I(10)$ & $10(20)$ & $5(11)$ & 62(6) \\
\hline \multicolumn{2}{|c|}{ Fracture of the facial bones } & $5(1)$ & $19(4)$ & $4(8)$ & $6(13)$ & $34(3)$ \\
\hline \multicolumn{2}{|c|}{ Fracture of the cervical spine } & $0(0)$ & $0(0)$ & $\mathrm{I}(2)$ & $0(0)$ & $I(0)$ \\
\hline \multicolumn{2}{|c|}{ Dislocation/sprain of joint or } & $4(1)$ & $16(4)$ & $3(6)$ & $6(13)$ & $29(3)$ \\
\hline \multicolumn{2}{|c|}{ ligaments of the head } & $293(60)$ & I83(43) & $13(27)$ & $15(32)$ & $504(50)$ \\
\hline \multicolumn{2}{|l|}{ Surgery } & & & & & \\
\hline Yes & & $I(0)$ & $6(3)$ & $7(39)$ & $5(33)$ & $19(4)$ \\
\hline No & & $300(100)$ & $202(97)$ & $\mathrm{II}(6 \mathrm{I})$ & $10(67)$ & $523(96)$ \\
\hline Mechanical & entilation & & & & & \\
\hline Yes & & $I(0)$ & $4(2)$ & $6(33)$ & II (73) & $22(4)$ \\
\hline No & & $300(100)$ & 204(98) & $12(67)$ & $4(27)$ & $520(96)$ \\
\hline Antiseizure & ledication & & & & & \\
\hline Yes & & $\mathrm{I}(0)$ & $10(5)$ & $6(33)$ & $12(80)$ & 29(5) \\
\hline No & & $300(100)$ & 198(95) & $12(67)$ & $3(20)$ & $513(95)$ \\
\hline Hyperosmc & medication & & & & & \\
\hline Yes & & $46(15)$ & $97(47)$ & $\mathrm{II}(6 \mathrm{I})$ & $14(93)$ & $168(31)$ \\
\hline No & & $255(85)$ & III(53) & $7(39)$ & $I(7)$ & $374(69)$ \\
\hline Other part & f body & & & & & \\
\hline Thorax & Soft tissue injury & $7(12)$ & $12(9)$ & $2(11)$ & $4(9)$ & $25(10)$ \\
\hline & Fractures & $0(0)$ & $5(4)$ & $3(17)$ & $3(7)$ & II(4) \\
\hline & Sprains/strains & $\mathrm{I}(2)$ & $5(4)$ & $2(11)$ & $4(9)$ & $12(5)$ \\
\hline & Injuries to internal organs & $0(0)$ & $0(0)$ & $0(0)$ & $3(7)$ & $3(1)$ \\
\hline
\end{tabular}

(Continued) 
Table 4 (Continued).

\begin{tabular}{|c|c|c|c|c|c|c|}
\hline & & 0 to I Day & 2-7 Days & 8-15 Days & $\begin{array}{c}\text { More Than } 15 \\
\text { Days }\end{array}$ & Total \\
\hline & & $\mathbf{N}(\%)$ & $\mathbf{N}(\%)$ & $\mathbf{N}(\%)$ & $\mathbf{N}(\%)$ & \\
\hline \multirow[t]{4}{*}{ Abdomen } & Soft tissue injury & $\mathrm{I}(2)$ & $6(4)$ & $I(6)$ & $4(9)$ & $12(5)$ \\
\hline & Fractures & $0(0)$ & $\mathrm{I}(\mathrm{I})$ & $0(0)$ & $0(0)$ & $I(0)$ \\
\hline & Sprains/strains & $0(0)$ & $2(1)$ & $0(0)$ & $4(9)$ & $6(2)$ \\
\hline & Injuries to internal organs & $0(0)$ & $0(0)$ & $0(0)$ & $4(9)$ & $4(2)$ \\
\hline Upper & Soft tissue injury & $23(39)$ & $24(18)$ & $3(17)$ & $3(7)$ & $53(20)$ \\
\hline \multirow[t]{2}{*}{ Extremities } & Fractures & $4(7)$ & II(8) & $2(I I)$ & $3(7)$ & $20(8)$ \\
\hline & Sprains/strains & $7(12)$ & $15(11)$ & $2(I I)$ & $3(7)$ & $27(10)$ \\
\hline Lower & Soft tissue injury & $13(22)$ & $25(18)$ & $I(6)$ & $4(9)$ & 43(17) \\
\hline \multirow[t]{2}{*}{ Extremities } & Fractures & $\mathrm{I}(2)$ & $13(10)$ & $I(6)$ & $3(7)$ & $18(7)$ \\
\hline & Sprains/strains & $2(3)$ & $17(13)$ & $I(6)$ & $4(9)$ & 24(9) \\
\hline
\end{tabular}

Notes: $*_{p}<0.05$ in a chi-square test of independence; categories with small cells not tested.

Table 5 TBI Management and Treatment

\begin{tabular}{|c|c|c|c|c|c|c|c|}
\hline & & Home & Unknown & Dead & Rehab & $\begin{array}{l}\text { Nursing Home/Long- } \\
\text { Term Care }\end{array}$ & Total \\
\hline \multirow{3}{*}{$\begin{array}{l}\text { CT scan } \\
\text { result }\end{array}$} & Normal & 327 & 18 & 0 & 0 & 0 & 345 \\
\hline & Abnormal & 72 & 4 & 5 & 1 & 3 & 85 \\
\hline & Total & 399 & 22 & 5 & $\mathbf{I}$ & 3 & 430 \\
\hline \multirow[t]{6}{*}{$\begin{array}{l}\text { Type of } \\
\text { injury }\end{array}$} & $\begin{array}{l}\text { Soft tissue injury to the scalp, face, or } \\
\text { neck }\end{array}$ & 354 & 22 & 6 & I & 3 & 386 \\
\hline & Fracture of the skull & 58 & I & 1 & 0 & 2 & 62 \\
\hline & Fracture of the facial bones & 24 & 5 & 3 & I & I & 34 \\
\hline & Fracture of the cervical spine & 0 & I & 0 & 0 & 0 & I \\
\hline & $\begin{array}{l}\text { Dislocation/sprain of joint or ligaments } \\
\text { of the head }\end{array}$ & 22 & 2 & 3 & 1 & I & 29 \\
\hline & Concussion & 471 & 23 & 6 & 1 & 3 & 504 \\
\hline \multirow{7}{*}{$\begin{array}{l}\text { CT } \\
\text { diagnosis }\end{array}$} & Traumatic cerebral edema & 1 & 0 & 1 & 0 & I & 3 \\
\hline & $\begin{array}{l}\text { Focal traumatic brain injury } \\
\text { (hematoma) }\end{array}$ & 107 & 9 & 6 & I & 2 & 125 \\
\hline & Epidural haemorrhage & 12 & I & 0 & 0 & 0 & 13 \\
\hline & Traumatic subdural haemorrhage & 10 & 0 & 4 & 0 & I & 15 \\
\hline & Secondary diffuse traumatic brain injury & 0 & 0 & 2 & 0 & 2 & 4 \\
\hline & Other & 96 & 15 & 5 & I & 3 & 120 \\
\hline & Unspecified intracranial injury & 2 & 0 & 2 & 0 & 0 & 4 \\
\hline \multicolumn{2}{|c|}{ Surgery performed } & 14 & 1 & 3 & 0 & 1 & 19 \\
\hline \multicolumn{2}{|c|}{ Mechanical ventilation } & 9 & 3 & 6 & I & 3 & 22 \\
\hline \multicolumn{2}{|c|}{ Antiseizure medication } & 16 & 4 & 5 & 1 & 3 & 29 \\
\hline \multicolumn{2}{|c|}{ Hyperosmolar medication } & $|4|$ & 18 & 6 & 1 & 2 & 168 \\
\hline \multicolumn{2}{|c|}{ ICP Monitor/ventriculostomy placed } & I & 0 & 0 & 0 & 0 & $\mathbf{I}$ \\
\hline
\end{tabular}


The results suggest that falls are the leading cause of TBI, while road traffic injuries rank first in mortality, which is similar to the findings from the published studies conducted in Northern Europe and the United States. ${ }^{8,17,19-21}$ The high incidence of fall-related TBIs among hospitalized patients highlighted the need for effective prevention strategies especially among children, that will be targeted to reducing indoor and outdoor hazards as well as minimizing risk-taking activities. ${ }^{22}$

Road traffic injury is the leading cause of TBI in LMICs, while in Georgia, despite the sharp growth of the road infrastructure over the last years, these are only in the 3rd place. According to the Ministry of Internal affairs of Georgia official data, the number of deaths caused by road traffic crashes decreased by $11 \%$ in 2018 compared to previous years. Using smart cameras for road traffic speed monitoring, zero tolerance to alcohol, criminalization of driving under the influence of drugs, introduction of a penalty points system, standard of using safety belts on front seat, and improving road infrastructure significantly affected the burden of road traffic injuries. $^{23}$

Violence-related TBIs might be misclassified and therefore underrepresented in this study. Violence, and especially domestic violence, is a stigmatized and a taboo subject in Georgian society. ${ }^{24}$ Also due to stigmatization, these data might also underestimate alcoholrelated TBIs. Georgia is internationally recognized for its wine production and an important component of the economy, which may also be related to low hospital alcohol screening.

Most of the TBI patients arrived at the hospital by ambulance, and most of the patients who were brought in within 1 hour were taken by ambulance, thus, hospital phase can be positively assessed according to time of addressing and the quality of the data, vital signs were $100 \%$ filled. However, most of the severely injured patients had both a longer time to hospital arrival and longer lengths of stay. The Challenges of timely hospital arrival in LMICs are having various aspects and features as prior studies recognized, and include self-treatment practices, primary care visits, and poor referral systems. ${ }^{25-27}$ The findings support the need for organized trauma systems that bring patients to trauma hospitals as quickly as possible. Future interventions, targeted on patient education regarding the timesensitive nature of TBI could address the delays in seeking care. ${ }^{5}$
The $99 \%$ (68 out of 69 ) of patients where CT scan or x-ray was not performed were very young children and clinically evaluated as mild TBIs and coded as concussions. The high percentage of scanned patients might be related to the financial accessibility of all emergency services including CT scan - which is an important tool for diagnosing and surgical decision-making processes, all of the emergency services are covered by the state program for all Georgian citizens. Thus, these patients would not need to make out-of-pocket payments as well as these high-standard hospitals would not have the logistical challenges.

A number of demographic and clinical variables of patients with TBI were associated with outcome. Besides the GCS score and extended time Interval between injury occurrence and hospital arrival, as a predictor of prolonged LOS and mortality in patients with TBI, other factors included lack of intracranial pressure monitoring. The patients with abnormal CTs requiring mechanical ventilation and surgical intervention needed longer lengths of hospital stay. All of the fatal outcomes were seen in severely injured TBI $(\mathrm{GCS}<9)$ patients. Mortality rate of severe TBI was $54 \%$ which is higher than other lowincome (40\%) and high-income settings (28\%). ${ }^{9,28}$ As the age of deceased patients ranged from 6 to 55 years, increased patient age did not seem to be related to mortality. These findings are consistent with the results of previously published studies ${ }^{5,29,30}$ Contrasted with those studies lack of CT availability, failure to receive surgery, and referral from another hospital were not factors associated with poor outcome in our settings.

One of the strengths of this study is that we were able to include all eligible TBI hospitalizations, and we had very little missing data. Our prospective study examined the TBI patients across over 70 variables and the data collectors have collected complete information about each patient based on medical histories/patients' charts as well as specifying details regarding missing variables in medical histories (ie place of injury occurrence), which helped to minimize the missing data.

The study also has some limitations that could influence the generalization of the results. This study was conducted with a small number of patients, in the limited time frame (6 months) of the research in the two largest multi-profile tertiary teaching hospitals located in the capital city, with low resource deficiency, thus it might not reflect what is happening in other settings especially in rural areas. 
Furthermore, our numbers do not include the TBI patients who were seen in the emergency department (ED) and were not hospitalized or did not receive TBIrelated care; thus these results are possibly underestimating the overall burden of TBI. We also have no follow-up of discharged patients; it is not possible to assess the longterm consequences of TBI among those patients as well as the true mortality rate.

There is a need for further studies using TBI registries which might expand and include all TBI in-patients and evaluate long-term outcomes of TBI for better understanding. Researchers suggest that organized trauma registries significantly reduce in-hospital and post-discharge mortality rates. ${ }^{31-33}$

\section{Conclusion}

In spite of the limitations, this study gives valuable insight into the burden and management of TBI in Georgia, provides a framework for TBI registry development, highlights areas for the research quality improvement, and provides information for policy makers regarding appropriate and effective preventive measures.

\section{Abbreviations}

TBI, traumatic brain injury; LMICs, low- and middleincome countries; WHO, World Health Organization; NCDC, National Center for Disease Control and Public Health of Georgia; INITIatE, International Collaboration to Increase Traumatic Brain Injury Surveillance in Europe; NIH, National Institutes of Health; EU, European Union; GCS, Glasgow Coma Scale; REDCap, Research electronic data capture application; SPSS, statistical package for social sciences; CT, computed tomography; iCREATE, Increasing Capacity for Research in Eastern Europe; ICU, Intensive care unit; ED, Emergency department; NVP, No visible pathology; TIL, therapy intensity level; LOS, length of stay.

\section{Ethics and Consent Statements}

Ethical clearance for conducting this study was secured by the Georgian National Centre for Disease Control and Public Health Institutional Review Board (IRB \#2018055 24.12.2018) in compliance with the ethical standards as laid down in the 1964 Declaration of Helsinki and its later amendments or comparable ethical standards.

There is no Institutional Review Board at Tbilisi State University (TSU). The NCDC is a training base for TSU, Department of Public Health, and the consent for ongoing research is usually obtained from the NCDC Institutional Review Board.

The data for this study were collected as a part of the patient medical record. Providers included information from patients (such as place of injury occurrence) in the medical record documentation that was preceded by the introduction of the study and obtaining verbal consent. The NCDC Institutional Review Board was convinced by the protocol that the study has no risk to the study participants and approved observational research using medical records without requiring prior written consent, which is in line with "International Ethical Guidelines for Epidemiological Studies" prepared by the Council for International Organizations of Medical Sciences (CIOMS) in collaboration with the World Health Organization (WHO) CIOMS Geneva February 2008.

Paper forms filled out by the data collectors did not allow patient identification - it did not include personally identifiable information (name, surname, ID number, or details that could identify the person), but allowed case identification with a medical record number. The research team ensured the secure storage of data in the REDCap system and all paper forms are stored securely in safe, locked cabinets at Tbilisi State University.

\section{Acknowledgments}

The work reported in this publication was funded by the NIH-Fogarty International Trauma Training Program iCREATE: Increasing Capacity for Research in Eastern Europe and INITIatE: International Collaboration to Increase Traumatic Brain Injury Surveillance in Europe, both at the University of Iowa and the Cluj School of Public Health (National Institutes of Health, Fogarty International Center 2D43TW007261 and 5R21N S098850).

The authors gratefully acknowledge all members of the iCREATE and INITIatE grants for their work on the project overall and for the contributions of project documentation used in this manuscript.

\section{Author Contributions}

All authors made a significant contribution to the work reported, whether that is in the conception, study design, execution, acquisition of data, analysis and interpretation, or in all these areas; took part in drafting, revising or critically reviewing the article; gave final approval of the version to be published; have agreed on the journal to 
which the article has been submitted; and agree to be accountable for all aspects of the work.

\section{Disclosure}

The authors report no conflicts of interest in this work.

\section{References}

1. Roozenbeek B, Maas AIR, Menon DK. Changing patterns in the epidemiology of traumatic brain injury. Nat Rev Neurol. 2013;9 (4):231-236. doi:10.1038/nrneurol.2013.22

2. Boniface R, Lugazia ER, Ntungi AM, Kiloloma O. Management and outcome of traumatic brain injury patients at muhimbili orthopaedic institute dar es salaam, Tanzania. Pan Afr Med J. 2017;26:1-7. doi:10.11604/pamj.2017.26.140.10345

3. Peeters W, van den Brande R, Polinder S, et al. Epidemiology of traumatic brain injury in Europe. Acta Neurochir. 2015;157 (10):1683-1696. doi:10.1007/s00701-015-2512-7

4. Li M, Zhao Z, Yu G, Zhang J. Epidemiology of traumatic brain injury over the world: a systematic review. Gen Med Open Access. 2016;04 (05):1-14. doi:10.4172/2327-5146.1000275

5. Kuo BJ, Vaca SD, Vissoci JRN, et al. A prospective neurosurgical registry evaluating the clinical care of traumatic brain injury patients presenting to Mulago National Referral Hospital in Uganda. PLoS One. 2017;12(10):1-16. doi:10.1371/journal.pone.0182285

6. Hofman K, Primack A, Keusch G, Hrynkow S. Addressing the growing burden of trauma and injury in low- and middle-income countries. Am J Public Health. 2005;95(1):13-17. doi:10.2105/ AJPH.2004.039354

7. Elahi C, Rocha TAH, da Silva NC, et al. An evaluation of outcomes in patients with traumatic brain injury at a referral hospital in Tanzania: evidence from a survival analysis. Neurosurg Focus. 2019;47(5):1-9. doi:10.3171/2019.7.FOCUS19316

8. Andelic N, Sigurdardottir S, Brunborg C, Roe C. Incidence of hospital-treated traumatic brain injury in the Oslo population. Neuroepidemiology. 2008;30(2):120-128. doi:10.1159/000120025

9. Staton CA, Msilanga D, Kiwango G, et al. A prospective registry evaluating the epidemiology and clinical care of traumatic brain injury patients presenting to a regional referral hospital in Moshi, Tanzania: challenges and the way forward. Int J Inj Contr Saf Promot. 2017;24(1):69-77. doi:10.1080/17457300.2015.1061562

10. Hyder AA, Wunderlich CA, Puvanachandra P, Gururaj G, Kobusingye OC. The impact of traumatic brain injuries: a global perspective. NeuroRehabilitation. 2007;22(5):341-353. doi:10.3233/ nre-2007-22502

11. Colantonio A, Saverino C, Zagorski B, et al. Hospitalizations and emergency department visits for TBI in Ontario. Can J Neurol Sci. 2010;37(6):783-790. doi:10.1017/S0317167100051441

12. Mehmood A, Zia N, Hoe C, Kobusingye O, Ssenyojo H, Hyder AA. Traumatic brain injury in Uganda: exploring the use of a hospital based registry for measuring burden and outcomes. BMC Res Notes. 2018;11(1). doi:10.1186/s13104-018-3419-1

13. Demyttenaere SV, Nansamba C, Nganwa A, Mutto M, Lett R, Razek T. Injury in Kampala, Uganda: 6 years later. Can J Surg. 2009;52(5):146-150.

14. National Statistics Office of Georgia. Demographic situation in Georgia. 2018:138. Available from: http://abkhazia.gov.ge/index. php?lang_id=ENG\&sec_id=42. Accessed February 27, 2021.

15. Munivenkatappa A, Agrawal A, Shukla DP, Kumaraswamy D, Devi BI. Traumatic brain injury: does gender influence outcomes? Int $J$ Crit Illn Inj Sci. 2016;6(2):70-73. doi:10.4103/22295151.183024
16. Ma C, Wu X, Shen X, et al. Sex differences in traumatic brain injury: a multi-dimensional exploration in genes, hormones, cells, individuals, and society. Chin Neurosurg J. 2019;5(1):1-9. doi:10.1186/ s41016-019-0173-8

17. O'Keefe K. Traumatic brain injury. Emerg Med Serv Clin Pract Syst Overs. 2014;1:237-242. doi:10.1002/9781118990810.ch30

18. Mollayeva T, El-Khechen-Richandi G, Colantonio A. Sex \& gender considerations in concussion research. Concussion. 2018;3(1): CNC51. doi:10.2217/cnc-2017-0015

19. Critchley G, Memon A. Epidemiology of head injury. Head Inj a Multidiscip Approach. 2009;1-11. doi:10.1017/ CBO9780511576515.002

20. Gordon WA, Zafonte R, Cicerone K, et al. Traumatic brain injury rehabilitation: state of the science. Am J Phys Med Rehabil. 2006;85 (4):343-382. doi:10.1097/01.phm.0000202106.01654.61

21. Lagbas C, Bazargan-Hejazi S, Shaheen M, Kermah D, Pan D. Traumatic brain injury related hospitalization and mortality in California. Biomed Res Int. 2013;2013:1-9. doi:10.1155/2013/ 143092

22. Hyndman B Preventing fall-related injuries in children: an environmental scan of resources and evidence-informed best practices. 2019.

23. Office SA. Performance audit report. Tbilisi; 2018.

24. National Center For Disease Control and Public Health Georgia. National strategy for prevention and control of injury and violence (in Georgian); 2013. Available from: https://www.ncdc.ge/Handlers/ GetFile.ashx?ID=9ed670a5-c5e7-49e1-ae1b-11160f3dc229.

25. Vaca SD, Kuo BJ, Vissoci JRN, et al. Temporal delays along the neurosurgical care continuum for traumatic brain injury patients at a Tertiary Care Hospital in Kampala, Uganda. Clin Neurosurg. 2019;84(1):95-103. doi:10.1093/neuros/nyy004

26. Long C, Titus Ngwa Tagang E, Popat RA, Lawong EK, Brown JA, Wren SM. Factors associated with delays to surgical presentation in North-West Cameroon. Surgery. 2015;158(3):756-763. doi:10.1016/j. surg.2015.04.016

27. Gebrehiwot T, San Sebastian M, Edin K, Goicolea I. Health workers' perceptions of facilitators of and barriers to institutional delivery in Tigray, Northern Ethiopia. BMC Pregnancy Childbirth. 2014;14(1). doi:10.1186/1471-2393-14-137

28. De Silva MJ, Roberts I, Perel P, Edwards P, Kenward M. Patient outcome after traumatic brain injury in high-, middle- and low-income countries: analysis of data on 8927 patients in 46 countries. Int J Epidemiol. 2008;38:452458.

29. Okidi R, Ogwang DM, Okello TR, et al. Factors affecting mortality after traumatic brain injury in a resource-poor setting. BJS Open. 2020;4(2):320-325. doi:10.1002/bjs5.50243

30. Béavogui K, Koïvogui A, Loua TO, Baldé R, Diallo B. Traumatic brain injury related to motor vehicle accidents in guinea: impact of treatment delay, access to healthcare, and patient's financial capacity on length of hospital stay and in-hospital mortality. $J$ Vasc Interv Neurol. 2015;8(4):30-38.

31. Ghodsi Z, Rahimi Movaghar V, Zafarghandi M, et al. The minimum dataset and inclusion criteria for the national trauma registry of Iran: a qualitative study. Arch Trauma Res. 2016;6(2). doi:10.5812/ atr.39725

32. Mann NC, Mullins RJ, MacKenzie EJ, Jurkovich GJ, Mock CN. Systematic review of published evidence regarding trauma system effectiveness. J Trauma Acute Care Surg. 1999;47(3 Suppl):S25S33. doi:10.1097/00005373-199909001-00007

33. MacKenzie EJ, Rivara FP, Jurkovich GJ, et al. A national evaluation of the effect of trauma-center care on mortality. $N$ Engl J Med. 2006;354:366-378. doi:10.1056/NEJMsa052049 


\section{Publish your work in this journal}

Risk Management and Healthcare Policy is an international, peerreviewed, open access journal focusing on all aspects of public health, policy, and preventative measures to promote good health and improve morbidity and mortality in the population. The journal welcomes submitted papers covering original research, basic science, clinical \& epidemiological studies, reviews and evaluations,

guidelines, expert opinion and commentary, case reports and extended reports. The manuscript management system is completely online and includes a very quick and fair peer-review system, which is all easy to use. Visit http://www.dovepress.com/testimonials.php to read real quotes from published authors.

Submit your manuscript here: https://www.dovepress.com/risk-management-and-healthcare-policy-journal 